\title{
Ruptured sinus of Valsalva aneurysm: Transaortic repair may cause sinus of Valsalva distortion and aortic regurgitation
}

Sung-Ho Jung, MD, ${ }^{a}$ Tae-Jin Yun, MD, PhD, ${ }^{a}$ Yu-Mi Im, MS, ${ }^{a}$ Jeong-Jun Park, MD, ${ }^{a}$ Hyun Song, MD, Jae-Won Lee, MD, ${ }^{b}$ Dong-Man Seo, MD, and Moo-Song Lee, MD, $\mathrm{PhD}^{\mathrm{c}}$

From the Division of Pediatric Cardiac Surgery, ${ }^{\text {a }}$ Department of Thoracic and Cardiovascular Surgery, ${ }^{b}$ and Department of Preventive Medicine, ${ }^{\mathrm{c}}$ Asan Medical Center, College of Medicine, University of Ulsan, Seoul, Korea.

Received for publication Oct 18, 2007; revisions received Dec 21, 2007; accepted for publication Jan 3, 2008.

Address for reprints: Tae-Jin Yun, M.D., PhD, Divisional Head, Division of Pediatric Cardiac Surgery, Asan Medical Center, 3881 Poongnap-dong, Song-pa gu, Seoul, Republic of Korea, 138-736 (E-mail: tjyun@ amc.seoul.kr).

J Thorac Cardiovasc Surg 2008;135:1153-8 0022-5223/\$34.00

Copyright (C) 2008 by The American Association for Thoracic Surgery

doi:10.1016/j.jtcvs.2008.01.004
Objectives: Recurrent or newly developing aortic regurgitation is a critical problem after the repair of ruptured sinus of Valsalva aneurysm.

Methods: A retrospective review of 56 patients who underwent surgical repair of ruptured sinus of Valsalva aneurysm between June 1990 and August 2006 was performed. Rupture of the right coronary sinus into the right ventricle was the most common anatomic type $(39 / 56,69.6 \%)$. Preoperative aortic regurgitation equal to or greater than grade II ( $\mathrm{n}=8,17.9 \%)$ was managed by repair (aortic valvuloplasty, $\mathrm{n}=5$ ) or replacement $(\mathrm{n}=3)$. Ruptured sinus of Valsalva aneurysm was repaired primarily $(n=7)$ or by patching $(n=10)$ through an aortotomy in 17 patients (transaortic group). In the remaining patients $(n=39)$, ruptured sinus of Valsalva aneurysm was repaired primarily from the chamber into which the corresponding aortic sinus ruptured, and the aneurysmal sac was reinforced with a supporting patch (non-transaortic group).

Results: Median follow-up duration was 46 months (0.4-177 months). There were 2 late deaths. Excluding 3 patients with aortic valve replacement on aneurysm repair, 11 patients $(11 / 53,21 \%)$ had recurrent or new-onset significant aortic regurgitation ( $\geq \mathrm{II} / \mathrm{IV}$ ) during the follow-up period. By multivariable analysis, aortic valvuloplasty at initial operation was the only significant risk factor for postoperative aortic regurgitation $(P<.001)$. After adjustment, the non-transaortic approach appeared to be associated with a lower risk of postoperative aortic regurgitation, with marginal significance (hazard ratio $0.28 ; P=.058$ ). Five-year freedom from significant aortic regurgitation in the transaortic and non-transaortic groups was $68 \% \pm 12 \%$ and $94 \% \pm 4 \%$, respectively.

Conclusion: Transaortic repair of ruptured sinus of Valsalva aneurysm may cause postoperative aortic regurgitation by progressive distortion of the aortic sinus geometry.

$\mathrm{R}$ uptured sinus of Valsalva aneurysm (RSVA) is a rare congenital cardiac anomaly, ${ }^{1,2}$ albeit five times more frequent in Asian populations than in Western countries. ${ }^{3}$ RSVA usually originates from the right coronary sinus and less frequently from the noncoronary and left coronary sinuses. Association of other cardiac lesions is common, including aortic valve regurgitation and ventricular septal defect (VSD). Surgical repair can be performed with a low risk, ${ }^{4,5}$ and long-term outcome is excellent with a minimal risk of recurrent fistula or VSD. ${ }^{4-7}$ However, the development of aortic regurgitation (AR), whether recurrent or de novo, is still a risk late after the surgical repair. It has been implied in previous studies that transaortic repair of RSVA after a precise geometric assessment of the sinus of Valsalva might reduce the incidence of late AR. ${ }^{7}$ Recently, we have developed a novel simplified repair technique that consists of (1) primary closure of the rupture site from the chamber into which the sinus of Valsalva ruptures and (2) placement of a supporting patch (or VSD patch if VSD is associated), which prevents bulging of the sinus of Valsalva aneurysm into the corresponding cardiac chamber. In comparison with our previous 


$$
\begin{aligned}
& \text { Abbreviations and Acronyms } \\
& \begin{aligned}
\text { AR } & =\text { aortic regurgitation } \\
\text { RA } & =\text { right atrium } \\
\text { RSVA } & =\text { ruptured sinus of Valsalva aneurysm } \\
\text { RV } & =\text { right ventricle } \\
\text { VSD } & =\text { ventricular septal defect }
\end{aligned}
\end{aligned}
$$

results with the transaortic repair technique, we have inferred from our recent experience that the non-transaortic approach might be associated with a lower risk of the later development of AR. In this study, we sought to determine the impact of surgical approaches on the development of recurrent or newly developing postoperative AR after adjusting other risk factors.

\section{Materials and Methods}

From June 1990 to August 2006, 56 consecutive patients underwent repair of RSVA at our institution. Mean age at operation was $33.2 \pm$ 11.4 years (14-64 years), and 34 were male. Patients with a connective tissue disorder or aortic root dilatation were excluded from this study. Symptoms at presentation were dyspnea on exertion (most common, 39.3\%), palpitation, chest pain or discomfort, cough, and fever. Fourteen (25\%) were free of symptoms, with the diagnosis having been made incidentally during routine examinations. Associated cardiac lesions were present in 44 patients. VSD was the most common cardiac anomaly $(41 / 56,73.2 \%$; subarterial type in 32, perimembranous type in 5, and muscular outlet type in 4), followed by AR ( $\geq \mathrm{II} / \mathrm{IV})$ in 8 , infundibular stenosis in 4 , atrial septal defect in 3 , tricuspid regurgitation in 2, mitral regurgitation in 2 , patent ductus arteriosus in 1 , subaortic membrane in 1 , and atrial fibrillation in 1. Among the 41 patients with VSD, 32 had interventricular communication. In the remaining 9, the VSD was completely occluded by the sinus of Valsalva aneurysm. Rupture of the right coronary sinus into the right ventricle $(\mathrm{RV})$ was the most common anatomic type $(39 / 56,69.6 \%)$, followed by rupture of the noncoronary sinus into the right atrium (RA) $(8 / 56,14.3 \%)$, rupture of the right coronary sinus into the RA $(7 / 56,12.5 \%)$, and rupture of the noncoronary sinus into the RV $(2 / 56,3.6 \%)$ (Table 1$)$. For the retrospective review and collation of the data, an ethics approval of human subject database research (No. 2007-0474) was obtained from the institutional review board of the hospital.

\section{Surgical Techniques}

Surgical repair was carried out using cardiopulmonary bypass with moderate hypothermia. After the aorta was crossclamped, the RA (in RSVA to RA or RV inlet) or the main pulmonary artery (in RSVA to RV outlet) was opened, the fistula opening was clamped with a vascular clamp, and cardioplegic solution was delivered antegradely through the root cannula. If there was significant AR, the aorta was obliquely opened and cardioplegic solution was delivered directly through the coronary ostia. In 4 patients, retrograde cardioplegia was used according to the surgeon's preference. The RSVA was repaired primarily $(\mathrm{n}=7)$ or by patching $(\mathrm{n}=10)$ through an aortotomy in 17 patients (transaortic group). In the remaining
TABLE 1. Origin of sinus of Valsalva aneurysm and cardiac chamber into which aneurysm ruptures

\begin{tabular}{lrrc}
\hline & RA & RV & Total \\
\hline RCS & 7 & 39 & 46 \\
NCS & 8 & 2 & 10 \\
Total & 15 & 41 & 56 \\
\hline
\end{tabular}

$R A$, Right atrium; $R V$, right ventricle; $R C S$, right coronary sinus; $N C S$, noncoronary sinus.

patients $(n=39)$, the RSVA was repaired primarily without excising the aneurysm from the chamber into which the corresponding aortic sinus ruptured, and the sinus of Valsalva aneurysm was reinforced with a supporting patch (non-transaortic group). In patients with RSVA to the RA ( $n=5 / 39$ ), tricuspid septal and anterior leaflets were detached from the annulus, and a Dacron patch was placed in the firm fibrotic portion in the atrial side and muscular margin in the RV side, encompassing the whole aneurysmal sac and the membranous ventricular septum. After the supporting patch was placed, previously detached tricuspid leaflets were reattached to the Dacron patch (Figure 1). In patients with RSVA to the RV through VSD (with or without interventricular communication) ( $\mathrm{n}=34 / 39$ ), a patch for VSD closure also functioned as a supporting patch for the sinus of Valsalva aneurysm (Figure 2). Coexisting significant AR $(n=8 / 56)$ was repaired $(n=5)$ by Trusler's technique or replaced $(n=3)$ with mechanical valves. Another patient with grade I AR received aortic valve repair owing to severe right coronary cusp prolapse (aortic valve resuspension). Thus 6 patients underwent aortic valve repair at the initial operation. Aortic valve abnormalities in 9 patients who underwent aortic valve intervention were right coronary cusp prolapse only in 3 , thinning and elongation of all leaflets in 3, thickening and fibrosis of all leaflets in 1, right coronary cusp prolapse with thickening in 1 , and right coronary cusp prolaspe with subaortic membrane in 1 . One patient without aortic valve intervention had a bicuspid aortic valve. Other procedures associated with RSVA repair were relief of infundibular stenosis in 4, atrial septal defect closure in 3, tricuspid valve repair in 2, mitral valve repair in 2, patent ductus arteriosus ligation in 1, subaortic membrane excision in 1 , and biatrial maze operation in 1. Cardiopulmonary bypass time (non-transaortic group, $116 \pm 31.9$ minutes; transaortic group, $104.1 \pm 42.4$ minutes) and aortic crossclamping time (non-transaortic group, $70.5 \pm 19.9$ minutes; transaoartic group, $67.8 \pm 30.7$ minutes) were comparable between the two groups. Patients without aortic valve replacement were given aspirin for 2 or 3 months postoperatively.

\section{Data Analysis}

Data are presented as frequencies, medians with ranges, or means with standard deviations. Freedom from adverse events (ie, recurrent or newly developing significant AR, reoperation, and death) was represented by the Kaplan-Meier method. Stratified survival curves were plotted to explore unadjusted group differences for variables of interest. After exclusion of the patients who underwent aortic valve replacement, the Cox proportional hazards model was fitted for time to significant AR, adjusting preoperative risk factors. Analyses were conducted with SPSS version 12.0 (Korean version; SPSS, Inc, Chicago, Ill). 

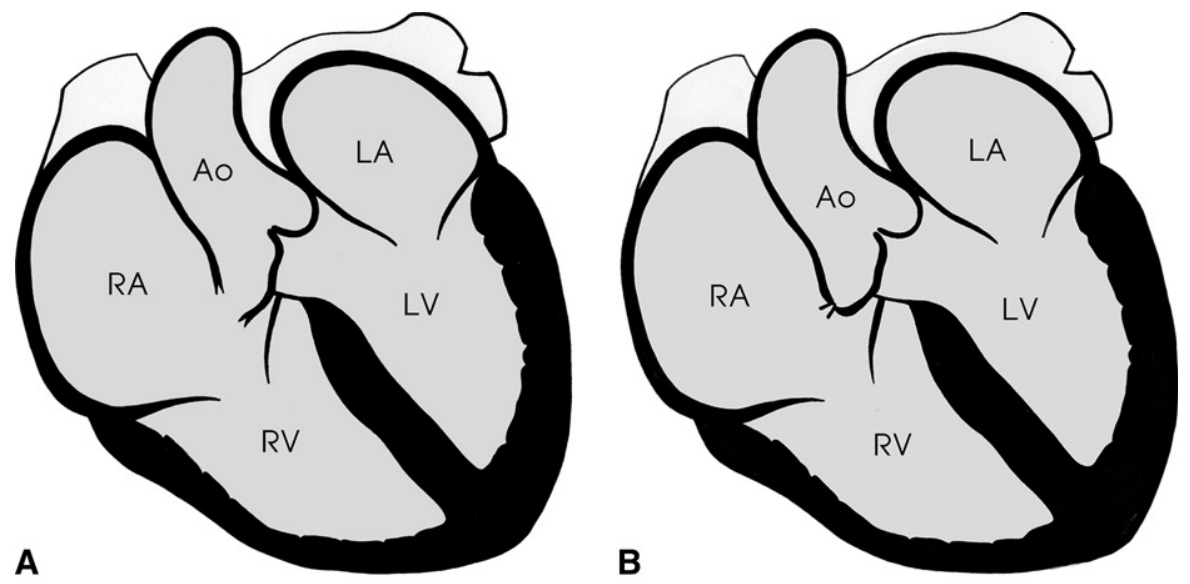

Figure 1. Surgical technique used for the repair of RSVA to the RA. A, RSVA to the RA. B, Primary closure of fistulous communication. C, Detachment of tricuspid leaflets. D, Placement of a Dacron patch to support the sinus of Valsalva aneurysm and membranous septum. E, Transaortic patch repair of RSVA. RSVA, Ruptured sinus of Valsalva aneurysm; $R A$, right atrium; $R V$, right ventricle; $L A$, left atrium; $L V$, left ventricle; Ao, aorta;
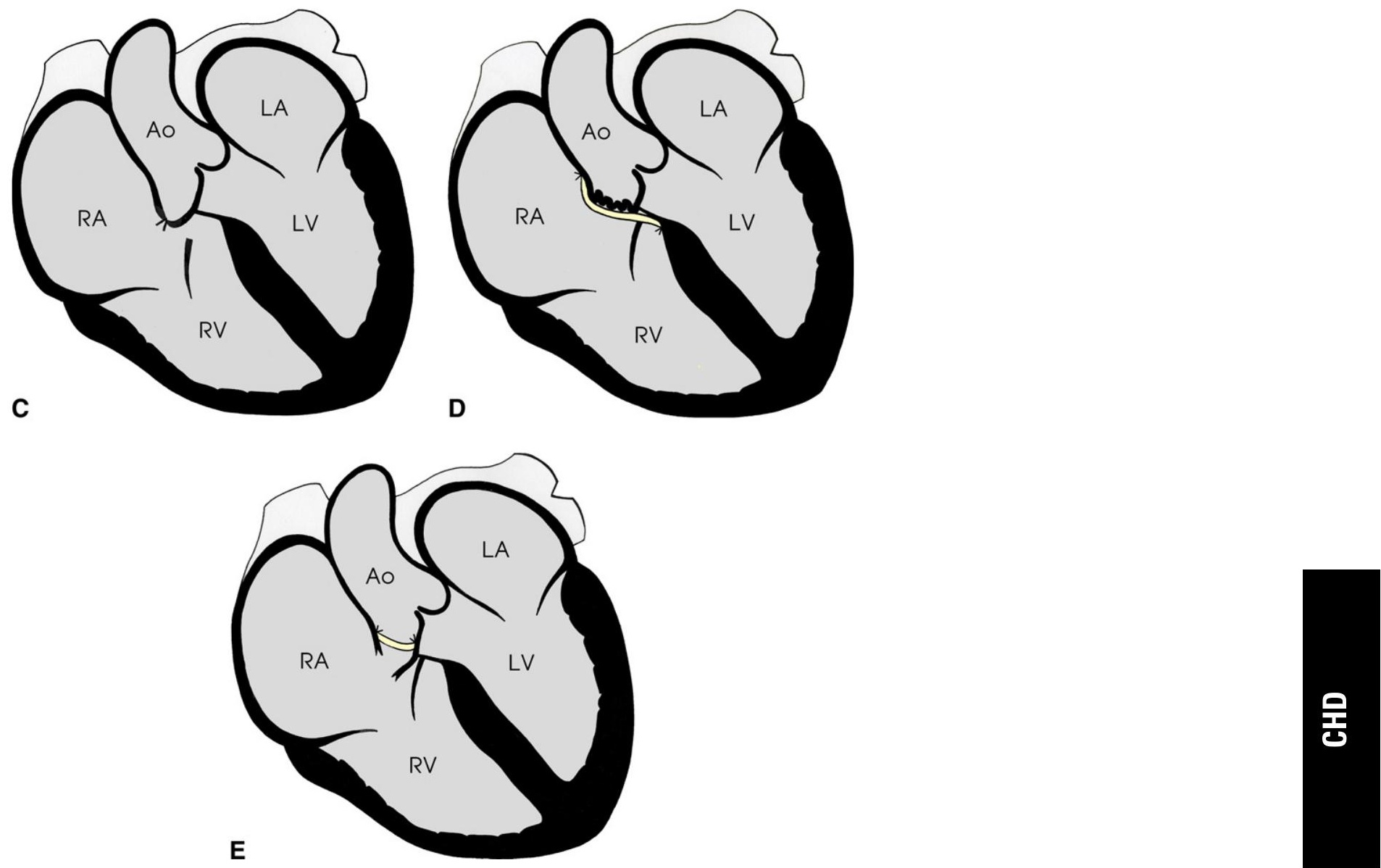

\section{Results}

There were no early deaths. Median follow-up duration was 46 months (0.4-177 months). There were 2 late deaths: one patient died at reoperation for para-aortic abscess 65 months after transaortic repair, and the other patient died of unknown causes 65 months after non-transaortic repair. Survival at 5 and 8 years in all patients was $100 \%$ and $91 \%$, respectively, and freedom from reoperation at 5 and 8 years in all patients was $92 \%$ and $77 \%$, respectively. One patient, who had transaortic primary repair of RSVA without a supporting patch, underwent reoperation for recurrent fistula 8 years postoperatively. Excluding 3 patients with aortic valve replacement on RSVA repair, 11 patients $(11 / 53,21 \%)$ had recurrent or new-onset significant AR ( $\geq \mathrm{II} / \mathrm{IV}$ ) during the follow-up period, and, among them, 4 underwent aortic valve replacement (Table 2). By univariable analysis, preoperative significant 

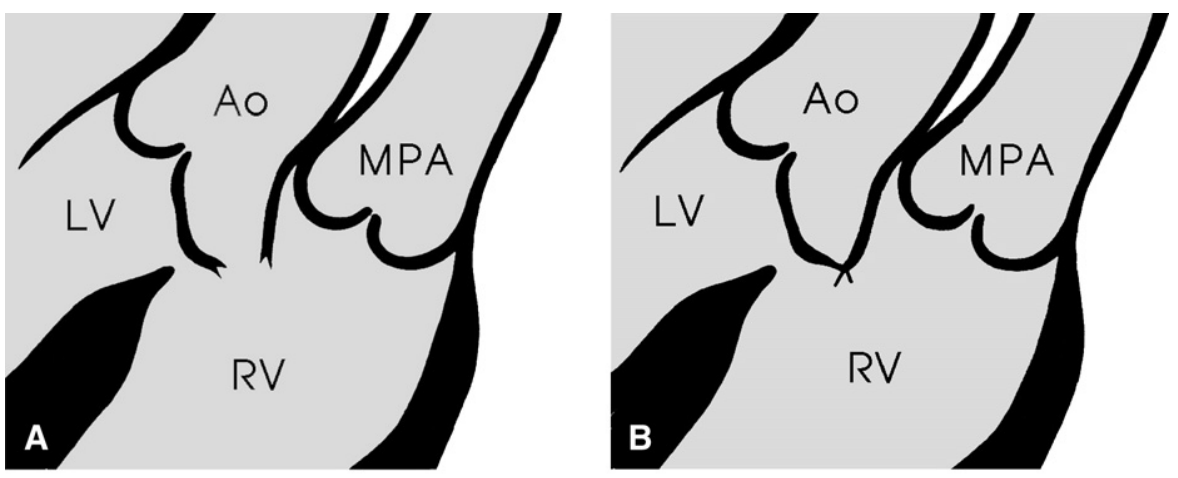

Figure 2. Surgical technique used for the repair of RSVA to the RV. A, RSVA to the RV outflow tract. B, Primary closure of fistulous communication. C, Placement of a Dacron patch to close VSD and to support the sinus of Valsalva aneurysm. D, Transaortic patch repair of RSVA. RSVA, Ruptured sinus of Valsalva aneurysm; VSD, ventricular septal defect; $R V$, right ventricle; $L V$, left ventricle; Ao, aorta; MPA, main pulmonary artery
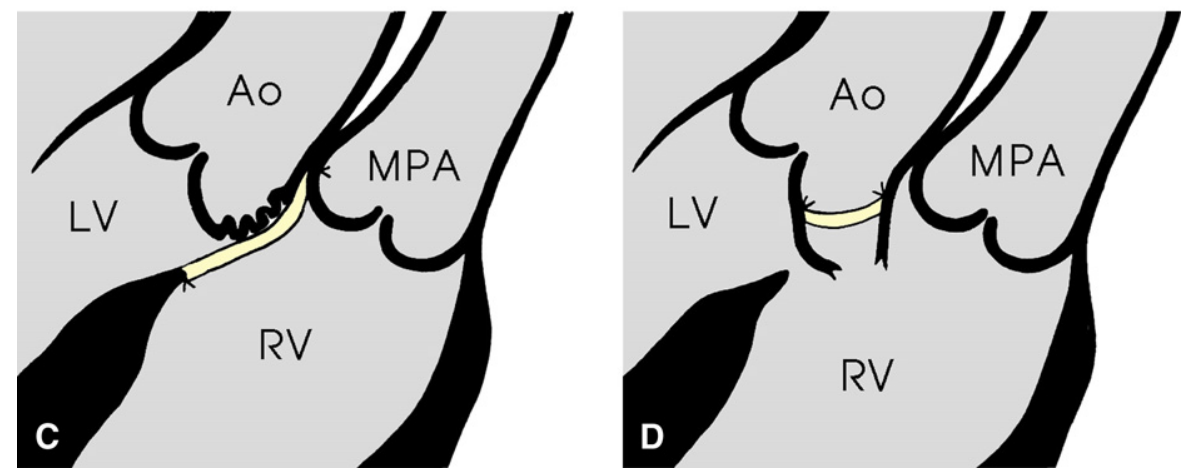

AR $(P=.001)$ and aortic valvuloplasty on RSVA repair $(P<.001)$ were identified as risk factors for decreased duration to significant AR. By multivariable analysis, however, aortic valvuloplasty at initial operation was identified as the only significant risk factor for postoperative AR $(P<.001)$. After adjustment, the non-transaortic approach appeared to be associated with a lower risk of postoperative AR with marginal significance (hazard ratio $0.28 ; P=.058$ ) (Table 3 ). Freedom from significant $A R$ at 5 years in all patients, in the transaortic group, and in the non-transaortic group was $86 \% \pm 5 \%, 68 \%$ $\pm 12 \%$, and $94 \% \pm 4 \%$, respectively (Figures 3 and 4 ).

\section{Discussion}

The first description of sinus of Valsalva aneurysm with intracardiac rupture is attributed to Hope (by Barragry and associates $^{8}$ ), and Lillehei, Stanley, and Varco 9 reported the first clinical case of successful surgical correction in 1957. Although the pathogenesis of this rare anomaly can be secondary

TABLE 2. Profiles of patients with recurrent or newly developing AR

\begin{tabular}{|c|c|c|c|c|c|c|}
\hline Op age/sex & Preop AR & RSVA & AVP & Approach & AR-free duration & Reop (interval) \\
\hline $64 / F$ & 0 & NCS-RA & - & Transaortic & $7 y$ & - \\
\hline $16 / F$ & III & RCS-RV & + & Non-transaortic & $11 y$ & - \\
\hline $22 / \mathrm{F}$ & II & RCS-RV & + & Transaortic & $1 \mathrm{~d}$ & $\operatorname{AVR}(1 \mathrm{~d})$ \\
\hline $32 / F$ & 0 & RCS-RV & - & Transaortic & $16 \mathrm{mo}$ & - \\
\hline $30 / \mathrm{M}$ & 0 & NCS-RV & - & Non-transaortic & $5 y$ & - \\
\hline $20 / \mathrm{M}$ & II & RCS-RV & + & Transaortic & $7 d$ & AVR (3 mo) \\
\hline $40 / \mathrm{M}$ & 1 & RCS-RV & + & Non-transaortic & $7 d$ & - \\
\hline $25 / F^{*}$ & III & NCS-RA & + & Transaortic & $4 \mathrm{mo}$ & AVR (5 y) \\
\hline $43 / \mathrm{M}$ & I & RCS-RV & - & Non-transaortic & $5 y$ & - \\
\hline $40 / \mathrm{M} \dagger$ & II & RCS-RV & + & Non-transaortic & $7 d$ & AVR $(6 \mathrm{mo})$ \\
\hline $22 / \mathrm{M}$ & 1 & RCS-RV & - & Transaortic & $7 d$ & - \\
\hline
\end{tabular}

$A R$, Aortic regurgitation; Op, operation; $R S V A$, anatomic types of ruptured sinus of Valsalva aneuryms; AVP, aortic valvuloplasty on RSVA repair; Reop, reopeation for $\mathrm{AR}, N C S$, noncoronary sinus; $R A$, right atrium; $R C S$, right coronary sinus; $R V$, right ventricle; $A V R$, aortic valve replacement. *This patient died at reoperation; $\nmid A R$ of this patient was aggravated from grade II to grade IV by subacute bacterial endocarditis. 
TABLE 3. Risk factors for recurrent or newly developing AR

\begin{tabular}{lccc}
\hline \multicolumn{1}{c}{ Risk factor } & $\begin{array}{c}\boldsymbol{P} \text { value } \\
\text { (univariable) }\end{array}$ & $\begin{array}{c}\boldsymbol{P} \text { value } \\
\text { (multivariable) }\end{array}$ & Hazard ratio \\
\hline Age at operation & .925 & - & - \\
Male gender & .912 & - & - \\
Subarterial-type VSD & .358 & - & - \\
Rupture of RCS & .549 & - & - \\
Primary closure of fistula & .980 & - & - \\
Preop significant AR & .001 & .14 & - \\
AVP & $<.001$ & $<.001$ & 14.01 \\
Non-transaortic approach & .082 & .058 & 0.28 \\
\hline
\end{tabular}

Italic type indicates statistical significance $A R$, Aortic regurgitation; VSD, ventricular septal defect; $R C S$, right coronary sinus; AVP, aortic valvuloplasty.

to syphilic or bacterial endocarditis, ${ }^{10}$ it is now generally believed that either a congenital lack of continuity between the aortic media and the annulus fibrosus ${ }^{11}$ or structural defect in the aortic annulus itself can gradually give way under aortic pressure to form an aneurysm. ${ }^{12}$ If there is a defect in the ventricular septum, which is the most commonly associated lesion, sinus of Valsalva aneurysm can protrude through the VSD into the RV. In some cases, protrusion of the aneurysmal sac completely obliterates the VSD, leaving no interventricular communication. In this study, among the 41 patients with VSD, there was no interventricular communication in 9 patients. Surgical repair of RSVA has evolved from simple primary closure with silk interrupted sutures ${ }^{9}$ to patching of the rupture site by a dual approach. ${ }^{4,6,7,13,14}$ Interventional closure in the catheterization laboratory has also been attempted. ${ }^{15}$ The optimal surgical approach, however, still remains

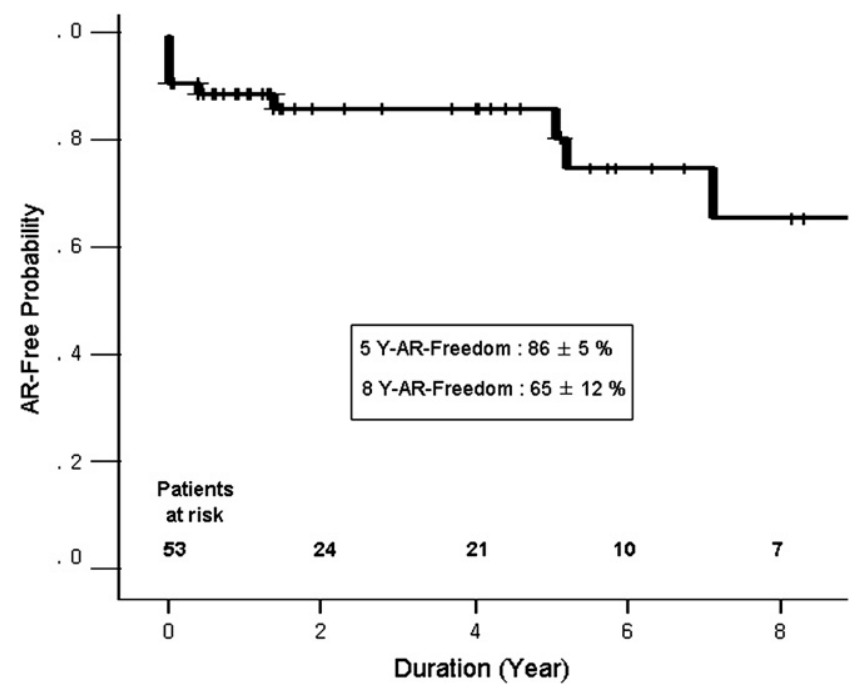

Figure 3. Freedom from significant AR excluding 3 who had AVR on RSVA repair ( $n=53$ ). $A R$, Aortic regurgitation; $A V R$, aortic valve replacement; 5 Y-AR-Freedom, 5-year freedom from significant $A R$; 8 Y-AR-Freedom, 8-year freedom from significant AR.

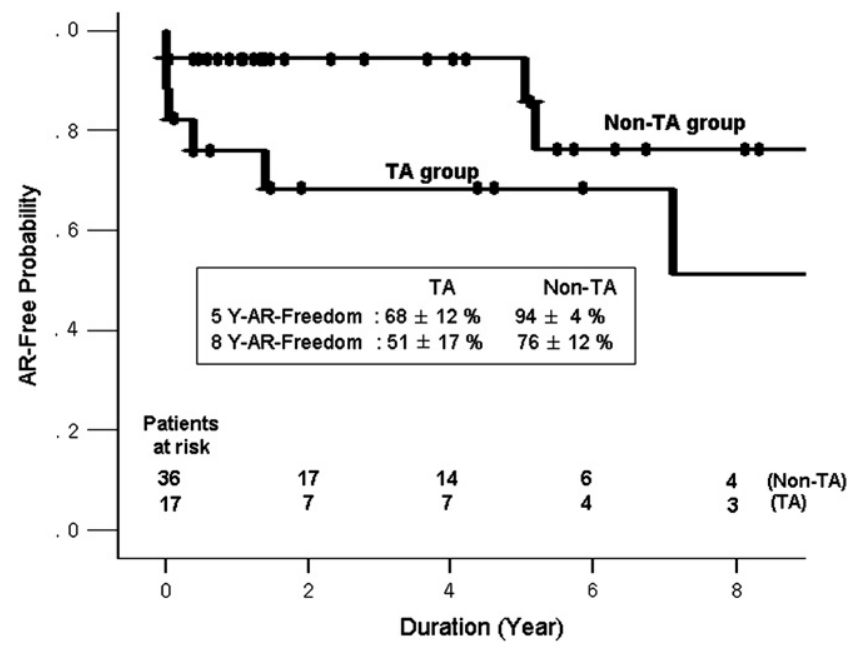

Figure 4. Freedom from significant $A R$ in transaortic (TA) group ( $n=17$ ) and non-transaoartic (non-TA) group $(n=36)$. $A R$, Aortic regurgitation; 5 Y-AR-Freedom, 5-year freedom from significant AR; 8 Y-AR-Freedom, 8-year freedom from significant AR.

to be defined. Controversies in surgical strategy center around RSVA closure technique (ie, primary closure vs patch closure), a surgical approach (transaortic vs non-transaortic), and placement of an additional supporting patch from the chamber into which the RSVA ruptures. Primary closure of RSVA can be performed at the base of the aneurysm (ie, origin of the fistula) or at the tip of the aneurysm (ie, outlet of the fistula). The former technique, which was used in the transaortic group in our series, is almost the same as the technique used for the repair of subarterial VSD associated with aortic valve prolapse and sinus of Valsalva aneurysm by Yacoub and associates ${ }^{16}$ in that both techniques aim at the elimination of the aneurysm base by suture obliteration (transaortic primary repair of the fistula in this study) or plication of the dilated sinus (Yacoub's technique). Given that RSVA is mostly found in the adult population whose sinus of Valsalva aneurysm tends to be rendered noncompliant at its base by fibrosis or calcification, however, application of Yacoub's technique for adult patients with RSVA may not be technically feasible; in addition, there is the risk of aortic sinus distortion. We believe that patients with primary closure of RSVA without a supporting patch would be predisposed to recurrent fistula, given that a primary closure-only strategy cannot resolve the major pathogenetic mechanism of RSVA (ie, lack of aortic media in the sinus of Valsalva). In our study, recurrent fistula developed in a patient who received primary closure of the RSVA through an aortotomy without a supporting patch. Recurrent fistula after primary closure of RSVA has also been reported in other series. ${ }^{4,8,10,17}$ Because early outcome is excellent and the risk of recurrent fistula is very low if repaired appropriately, late outcome is mainly determined by the competency of the aortic valve. It has been implied 
that association of subarterial type $\mathrm{VSD},{ }^{7}$ rupture to the $\mathrm{RV},{ }^{7}$ preoperative ${ }^{18}$ or immediate postoperative $\mathrm{AR},{ }^{19}$ bicuspid aortic valve, ${ }^{2,20}$ cusp disease of affected sinus, or aortic root dilatation ${ }^{20}$ may be risk factors for late AR. It was also suggested that repair of RSVA through an aortotomy, along with careful inspection of the aortic root complex and aortic valve repair, may reduce the incidence of late aortic insufficiency. ${ }^{7,14}$ To the contrary, our study showed that repair of the aortic opening of the fistula through an aortotomy might be a risk factor for recurrent or new-onset AR. It is unclear whether this finding is from progressive distortion of the aortic sinus geometry by the scar change around the prosthetic patch or from technical problems of our own. However, it is prudent to say that our simplified surgical approach is as effective as the conventional transaortic technique in fistula repair and may be better in terms of alleviating the risk of late AR. The theoretical advantages of our non-transaortic approach are as follows: (1) it is simple to perform (ie, no need for two patches), (2) no foreign material is left in the aortic sinus, and (3) the risk of distortion of the aortic sinus is minimized by preserving the geometry of the sinus of Valsalva. Given the fact that the sinus of Valsalva aneurysm is caused by a structural defect (ie, absence of aortic media), the surgical strategy restoring the integrity of the aortic sinus is deemed reasonable. One of the concerns regarding our technique might be thrombus formation inside the aneurysm because there still remains aneurysmal structure after the repair, albeit smaller than preoperative size. This is why we routinely prescribe anticoagulation therapy (ie, aspirin) for such patients for 2 or 3 months postoperatively. Another concern might be recurrent rupture of the primarily repaired site, which can lead to fistula formation between the aorta and the left ventricle. Because the aortic pressure is higher than the RA or RV pressure throughout the cardiac cycle, however, we believe that a sinus of Valsalva aneurysm, along with the repaired rupture site, would remain attached and finally adhere to the supporting patch. To date, we have not observed intra-aneurysmal thrombosis or recurrent fistula after using the non-transaortic repair.

In conclusion, this study showed that non-transaortic repair of RSVA showed an excellent outcome with a minimal risk of reoperation for recurrent fistula. The transaortic approach may be associated with a higher risk of postoperative AR by distorting the aortic sinus geometry. Therefore, aortotomy should be reserved only for those patients with significant AR necessitating a surgical intervention for the aortic valve.

\section{References}

1. Kouchoukos NT, Blackstone EH, Doty DB, Hanley FL, Karp RB. Cardiac surgery. 3rd ed. Oxford (UK): Churchill Livingstone; 2003. P. 911-22.

2. Takach TJ, Reul GJ, Duncan JM, Cooley DA, Livesay JJ, Ott DA, et al. Sinus of Valsalva aneurysm or fistula: management and outcome. Ann Thorac Surg. 1999;68:1573-7.

3. Chu SH, Hung CR, How SS, Chang H, Wang SS, Tsai CH, et al. Ruptured aneurysms of the sinus of Valsalva in Oriental patients. $J$ Thorac Cardiovasc Surg. 1990;99:288-98.

4. Vural KM, Sener E, Tasdemir O, Bayazit K. Approach to sinus of Valsalva aneurysms: a review of 53 cases. Eur J Cardiothorac Surg. 2001;20:71-6.

5. Dong C, Wu QY, Tang Y. Ruptured sinus of Valsalva aneurysm: a Beijing experience. Ann Thorac Surg. 2002;74:1621-4.

6. Zikri MA, Stewart RW, Cosgrove DM. Surgical correction of sinus of Valsalva aneurysm. J Cardiovasc Surg. 1999;40:787-91.

7. van Son JAM, Danielson GK, Schaff HV, Orszulak TA, Edwards WD, Seward JB. Long-term outcome of surgical repair of ruptured sinus of Valsalva aneurysm. Circulation. 1994;90(5 Pt 2):II20-9.

8. Barragry TP, Ring WS, Moller JH, Lillehei CW. 15- to 30-year followup of patients undergoing repair of ruptured congenital aneurysms of the sinus of Valsalva. Ann Thorac Surg. 1988;46:515-9.

9. Lillehei CW, Stanley P, Varco RL. Surgical treatment of ruptured aneurysm of the sinus of Valsalva. Ann Surg. 1957;146:459-72.

10. Lin CY, Hong GJ, Lee KC, Tsai YT, Tsai CS. Ruptured congenital sinus of Valsalva aneurysms. J Card Surg. 2004;19:99-102.

11. Edwards JE, Burchell HB. The pathological anatomy of deficiencies between the aortic root and the heart, including aortic sinus aneurysm. Thorax. 1957;12:125-39.

12. Taguchi K, Sasaki N, Matsuura Y, Uemura R. Surgical correction of aneurysm of the sinus of Valsalva: a report of forty-five consecutive patients including eight with total replacement of the aortic valve. Am J Cardiol. 1969;23:180-91.

13. Abe T, Komatsu S. Surgical repair and long-term results in ruptured sinus of Valsalva anerysm. Ann Thorac Surg. 1988;46:520-5.

14. Au WK, Chiu SW, Mok CK, Lee WT, Cheung D, He GW. Repair of ruptured sinus of Valsalva aneurysm: determinants of long-term survival. Ann Thorac Surg. 1998;66:1604-10.

15. Hijazi SM. Ruptured sinus of Valsalva aneurysm: management options. Catheter Cardiovasc Interv. 2003;58:135-6.

16. Yacoub MH, Khan H, Stavri G, Shinebourne E, Radley-Smith R. Anatomic correction of the syndrome of prolapsing right coronary aortic cusp, dilatation of the sinus of Valsalva, and ventricular septal defect. J Thorac Cardiovasc Surg. 1997;113:253-60.

17. Harkness JR, Fitton TP, Barreiro CJ, Alejo D, Gott VL, Baumgartner WA, et al. A 32-year experience with surgical repair of sinus of Valsalva aneurysm. J Card Surg. 2005;20:198-204.

18. Choudhary SK, Barn A, Sharma R, Airan B, Kumar AS, Venugopal P. Sinus of Valsalva aneurysm: 20 years' experience. J Card Surg. 1997; 12:300-8

19. Murashita T, Kubota T, Kamikubo Y, Shiiya N, Yasuda K. Long-term results of aortic valve regurgitation after repair of ruptured sinus of Valsalva aneurysm. Ann Thorac Surg. 2002;73:1466-71.

20. Azakie A, David TE, Peniston CM, Rao V, Williams WG. Ruptured sinus of Valsalva aneurysm: early recurrence and fate of the aortic valve. Ann Thorac Surg. 2000;70:1466-71. 